\section{Brain, Behavior and Evolution}

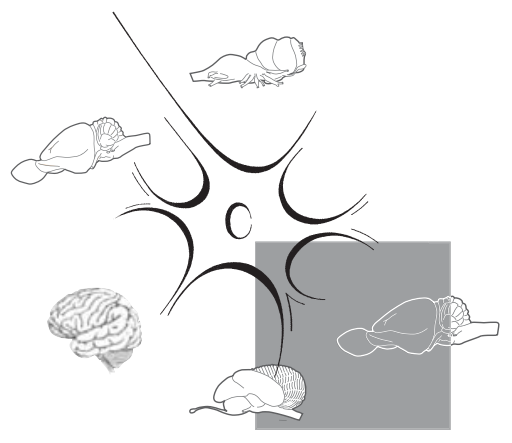

Highlights and Perspectives on Evolutionary Neuroscience

Published online: August 6, 2010 DOI: $10.1159 / 000313860$

\title{
Conflict over Cingulate Cortex: Between-Species Differences in Cingulate May Support Enhanced Cognitive Flexibility in Humans
}

\author{
A Response to Schall JD and Emeric EE (2010): Conflict in Cingulate \\ Cortex Function between Humans and Macaque Monkeys: \\ More Apparent than Real. Brain Behav Evol 75:237-238
}

\author{
Michael W. Cole ${ }^{b}$, Nick Yeung $^{a}$, Winrich A. Freiwald ${ }^{c}$, Matthew Botvinick ${ }^{d}$ \\ a Department of Experimental Psychology, University of Oxford, Oxford, UK; \\ ${ }^{b}$ Department of Psychology, Washington University, St. Louis, Mo.,

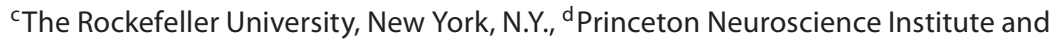 \\ Department of Psychology, Princeton University, Princeton, N.J., USA
}

Schall and Emeric [2010] provide a thoughtful commentary on our recent review of the discrepancies between functions attributed to the macaque monkey and the human anterior cingulate cortex (ACC) [Cole et al., 2009]. We agree with Schall and Emeric on many points. Indeed, our review considered the main point discussed in their commentary: the notion that effector differences might account for interspecies discrepancies because relevant studies have typically used saccades for monkeys versus forelimb movements for humans.

However, it is important to note, as we did in our paper, that two key studies challenge this argument. Both Curtis et al. [2005] (in humans) and Ford et al. [2009] (in monkeys) reported conflict-related fMRI activity in the ACC during saccade tasks, demonstrating that this region shows conflict sensitivity even when the task involves the same response modality as typical monkey studies. Together, these two studies challenge any straightforward account of interspecies discrepancies in terms of effector differences.

Thus, although we agree with Schall and Emeric that closer integration of meth- ods used in human and monkey studies is highly desirable, we maintain that the most plausible explanation of observed interspecies differences lies elsewhere. One plausible account is that conflict-related ACC activity reflects processes within the region, such as competition among groups of interneurons, that are better detected by fMRI (more often used in human studies) than single-unit activity recording (more often used in monkey studies). On this point, which Schall and Emeric do not challenge, we note that fMRI has been shown to be sensitive to a wider range of activity in other regions as well, such as in the frontal eye fields [Ford et al., 2009].

An alternative possibility is that only humans have a functional region in the dorso-caudal portion of the ACC that is sensitive to conflict. Strong anatomical evidence suggests that humans have a unique region (area 32') that may provide this function [Vogt et al., 1995]. Schall and Emeric argue that this same evidence suggests a homologous area 32 in monkeys and humans. However, this was not the conclusion of the authors of the studies in question, nor of Brodmann himself when he labeled those areas with the same num- ber between the species [see Öngür et al., 2003]. Schall and Emeric also suggest that area $32^{\prime}$ has been conclusively shown to correspond to the cingulate motor areas of macaques. However, the data are not conclusive: the evidence adduced by Schall and Emeric comes from a small meta-analysis of human-only group fMRI studies that involved cursory between-species anatomical comparison (i.e. no comparison of histology or connectivity) and no direct between-species comparison of function [Picard and Strick, 2001].

Schall and Emeric conclude by asking what deficit macaque monkeys should have without a conflict monitoring brain region. We agree that this is a key question for future research. One plausible hypothesis is that human area $32^{\prime}$ bestows enhanced cognitive flexibility by detecting conflicts in a wide variety of information processing contexts (i.e. not just motor conflicts). This kind of broad monitoring capability may provide humans with readily observable improvements in motivational and cognitive flexibility. Indeed, humans typically learn complex tasks quickly from instruction for little or no hedonic gain [Cole, 2009], while macaque

\section{KARGER}

Fax +4161306 1234 E-Mail karger@karger.ch www.karger.com
(C) 2010 S. Karger AG, Base

0006-8977/10/0754-0239\$26.00/0

Accessible online at:

www.karger.com/bbe
Michael W. Cole

Department of Psychology

Washington University, One Brookings Drive

St. Louis, MO 63130 (USA)

Tel. +1 314935 8181, Fax +1 314935 8790, E-Mail mwcole@ mwcole.net 
monkeys typically train for months to perform the same tasks (if they can at all), and only for juice reward. We suggest that monitoring for conflict in general information processing helps provide humans with a kind of 'adaptive focus' that facilitates rapid reduction of processing interference (e.g. using conflict adaptation) to optimize performance in a broad range of task domains and motivational contexts. A critical challenge for future research is to develop experimental paradigms capable of probing the existence of, and potential ACC contribution to, corresponding cognitive flexibility in non-human primates.

\section{References}

Cole MW, Yeung N, Freiwald WA, Botvinick M (2009): Cingulate cortex: diverging data from humans and monkeys. Trends Neurosci 32:566-574.

Cole MW (2009): The biological basis of rapid instructed task learning. Dissertation, University of Pittsburgh. http://etd.library.pitt. edu/ETD/available/etd-07152009-145850/.
Curtis C, Cole M, Rao V, D’Esposito M (2005): Canceling planned action: an fMRI study of countermanding saccades. Cereb Cortex 15 1281-1289.

Ford KA, Gati JS, Menon RS, Everling S (2009): Bold fMRI activation for anti-saccades in nonhuman primates. Neuroimage 45:470476.

Döngür D, Ferry A, Price J (2003): Architectonic subdivision of the human orbital and medial prefrontal cortex. J Comp Neurol 460:425449.
Picard N, Strick P (2001): Imaging the premotor areas. Curr Opin Neurobiol 11:663-672.

Schall JD, Emeric EE (2010): Conflict in cingulate cortex function between humans and macaque monkeys: more apparent than real. Brain Behav Evol 75:237-238.

Vogt BA, Nimchinsky EA, Vogt LJ, Hof PR (1995): Human cingulate cortex: surface features, flat maps, and cytoarchitecture. J Comp Neurol 359:490-506. 